Nordic Concrete Research - Publ. No. NCR 62 - ISSUE 1 / 2020 - Article 3, pp. 41-61

\begin{tabular}{|c|c|}
\hline$S$ sciendo & 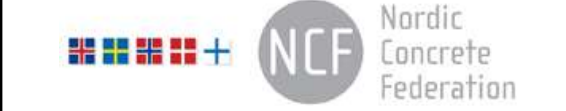 \\
\hline $\begin{array}{l}\text { (C) Article authors. This is an open access article } \\
\text { distributed under the Creative Commons Attribution- } \\
\text { NonCommercial-NoDerivs licens. } \\
\text { (http://creaticecommons.org/licenses/by.nc-nd/3.0/). }\end{array}$ & $\begin{array}{l}\text { ISSN online } 2545-2819 \\
\text { ISSN print } \quad 0800-6377\end{array}$ \\
\hline DOI: $10.2478 /$ ncr-2019-0005 & $\begin{array}{r}\text { Received: March 30, } 2020 \\
\text { Revision received: May 27, } 2020 \\
\text { Accepted: May 28, } 2020\end{array}$ \\
\hline
\end{tabular}

\title{
Non-destructive Test Methods for Corrosion Detection in Reinforced Concrete Structures
}

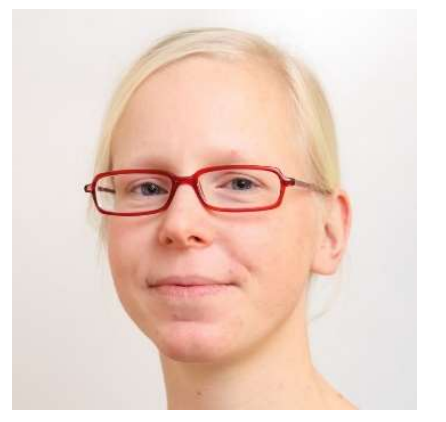

Hornbostel, Karla

$\mathrm{MSc}, \mathrm{PhD}$, Senior Engineer

Norwegian Public Roads Administration

Abels gate 5, NO-7030 Trondheim

karla.hornbostel@vegvesen.no

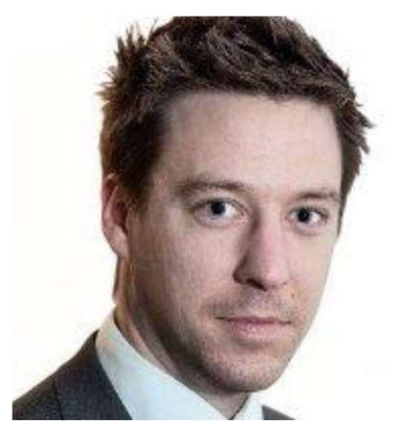

Tobias Danner

MSc, PhD, Research Scientist

SINTEF Community

Department Architecture, Materials and Structures

NO-7491 Trondheim

tobias.danner@sintef.no

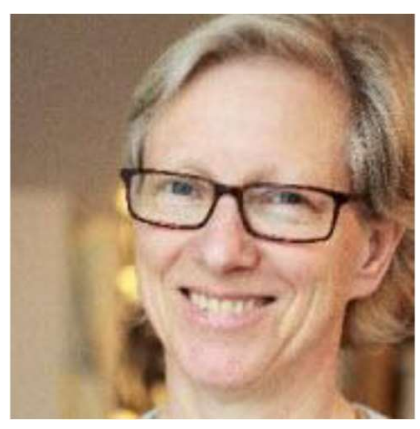

Mette Rica Geiker

MSc, PhD, Professor

Norwegian University of Science and Technology

Department of Structural Engineering

Richard Birkelandsvei 1a, NO-7491 Trondheim

mette.geiker@ntnu.no 


\begin{abstract}
Several inspection methods can be used to assess the corrosion state of steel reinforcement in concrete. Especially for periodical field surveys and monitoring, non-destructive testing (NDT) methods are to be preferred as they do not cause any or very limited damage to the existing concrete. In this paper, the corrosion state of three reinforced concrete beams exposed to marine environment for 25 years was evaluated by measuring three parameters; electrochemical potential, concrete resistivity and corrosion rate. The measurements were performed with commercial devices. It was found that all devices are applicable for field inspections. Among the methods selected for the study, the electrochemical potential measured in a fine grid and analysed statistically offered the best possibility of evaluating the corrosion state; preferably in combination with selected excavations for determination of the level of corrosion.
\end{abstract}

Key words: Non-destructive testing, reinforcement corrosion, potential measurement, concrete resistivity, corrosion rate

\title{
1. INTRODUCTION
}

Several inspection methods can be used to assess the corrosion state and the rate of steel reinforcement in concrete [1, 2]. For periodical field surveys and monitoring, non-destructive testing (NDT) methods are to be preferred as they do not cause any or very limited damage to the existing concrete. For inspection of the state of the reinforcement, NDT measurements are commonly performed directly on the concrete surface, either with or without an electrical connection to the reinforcement. Nevertheless, NDT should be accompanied by selected excavations (DT - destructive testing) for the purpose of calibrating the NDT measurements and determination of the actual level of corrosion. As possible supplement of visual inspections, measuring the electrochemical potential in combination with selected excavations is the most commonly used method for special inspections of the state of the reinforcement in marine structures.

The aim of this investigation was to compare the validity of selected parameters for characterisation of the corrosion state of the reinforcement affected by chloride induced corrosion and to assess the applicability of selected devices. The measurements were performed on 25 years old concrete beams from a Norwegian coastal field station. Three parameters were measured; electrochemical potential, concrete resistivity and corrosion rate. Different commercially available devices were used. One of the devices offered the possibility to measure all three parameters (electrochemical potential, concrete resistivity and corrosion rate) in the same operation ("three-in-one" device). The two separate devices gave the option of either measuring electrochemical potential or concrete resistivity. The study is meant to illustrate advantages and disadvantages of different techniques both with regard to the ability to characterise the corrosion state of the reinforcement and when it comes to applicability in practice. It must be underlined that the investigation was not undertaken to test specific equipment or suppliers, and the study is not meant to be used for any commercial purposes. 


\section{1}

\section{Measurement parameters}

\section{Electrochemical potential}

Potential measurements provide information about the difference in the electrochemical potential between the reinforcement bar and an external reference electrode that moves over the concrete surface. The potential difference measured can indicate whether the steel is passive or actively corroding. The principal execution of the method can be found in common literature and guidelines as e.g. [3]. The measured values can either be compared to tabulated values (see e.g. ASTM C 876 [4]) or potential differences can be interpreted statistically (see e.g. [3, 5, 6]). To the knowledge of the authors, all commercially available devices measuring the electrochemical potential are based on the same principle. An electrical connection is established to the reinforcement and potential differences are measured from the concrete surface against a chosen reference electrode (cf. Figure 1 a)).

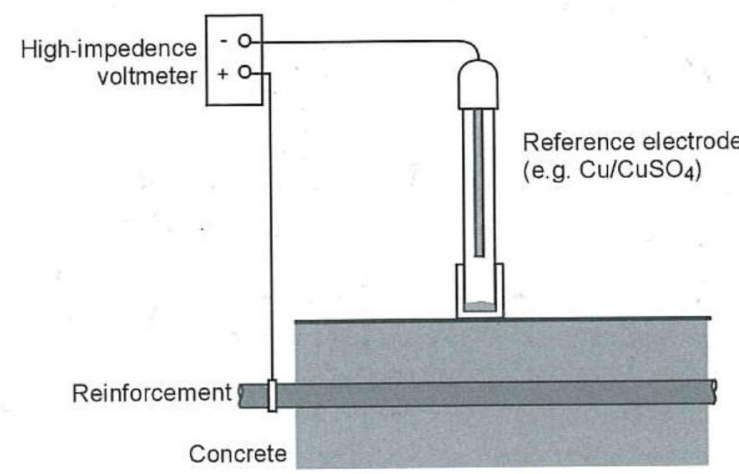

a)

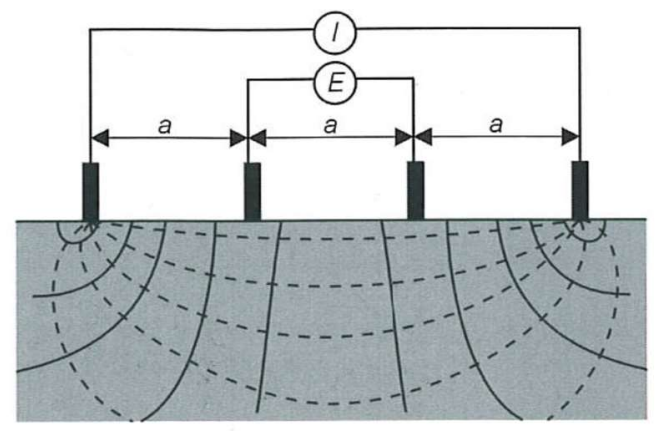

b)

Figure 1-NDT methods, a) Schematic representation of the measurement of potentials (from [1)] and b) Schematic representation of the four electrode technique to determine resistivity (from [1]).

\section{Electrical resistance/resistivity}

Electrical resistivity is a measure of the charge transport ability of a material and is independent of geometry. In concrete, it characterises the flow of ions in the cement paste matrix, which depends both on material properties (e.g. porosity, pore solution composition), and exposure conditions (degree of pore saturation, temperature). The degree of saturation has been identified as the main factor influencing concrete resistivity, followed by the temperature and quality of the concrete (cover) [7-10]. Since the electrochemical process of steel corrosion in concrete requires the transport of ions through the concrete, it is widely held that concrete resistivity is a central parameter for the corrosion process. However, other factors as oxygen availability and local effects at the steel-concrete interface also control the corrosion process of embedded reinforcement [11]. The resistivity of an existing concrete structure (cover concrete) is commonly measured either by i) recording the resistance between an external reference electrode/counter electrode setup and the reinforcement (an electrical connection to the reinforcement is needed) or ii) with four electrodes placed on the concrete surface where a current is sent between the two outer electrodes and the potential drop is measured between the two inner ones (cf. Figure $1 \mathrm{~b}$ )). More information and additional techniques can be found in common literature, e.g. [12]. 


\section{Corrosion rate}

The rate of corrosion is defined as the amount of metal removed from the metal surface over a time period (e.g. in $\mu \mathrm{m} /$ year). Measurements in the field give an instantaneous value of the rate of corrosion at the specific time of measuring. Instantaneous values measured over a large concrete surface can give an indication where corrosion is ongoing, and a high rate can be expected. Recorded several times during a period of time it gives valuable information about the rate of damage development and can thus give input parameters for service life modelling.

Different techniques for measuring corrosion rate have been developed, details and information can be found amongst others in [13]. All techniques aim at measuring the polarisation resistance, which is used to calculate the instantaneous corrosion rate $[14,15]$. The calculation itself is not straight forward and has its limitations, as is stated amongst others in [16-21]. Different methods are applied in commercial field equipment to measure the polarisation resistance. Often a threeelectrode setup is used including the embedded steel (working electrode (WE)), a counter (CE) and a reference electrode (RE). To confine the applied current, so-called guard-rings or electrodes can additionally be used. Linear polarisation resistance (LPR) measurements applied in commercial equipment measure the relationship between electrochemical potential and current. The relationship is measured either by monitoring the current response to small incremental potential steps or the potential response to small incremental current steps [22, 23]. Galvanostatic pulse measurements are another technique applied in commercial equipment with a threeelectrode setup. A short time anodic pulse is applied galvanostatically on the reinforcement and the resulted change in potential is monitored [24, 25]. For both LPR and pulse measurements the initial electrochemical potentials of the reinforcement as well as the electrical resistance of the concrete cover is determined during the measurement. Therefore, commercial equipment applying these techniques can be considered as "three-in-one" device, offering information about electrochemical potential, concrete resistivity and corrosion rate.

Another approach for measuring the polarisation resistance is electrical impedance spectroscopy (EIS). During EIS, an AC signal of small amplitude with changing frequencies is applied to the working electrode and the current response is measured. The data is analysed in BODE and/or NYQUIST plots and interpreted using appropriate equivalent circuit diagrams [26]. The measurements give also information about concrete resistivity, while electrochemical potential measurements are not included.

\section{2. \\ EXECUTION OF THE MEASUREMENTS}

Concrete beams from a field station in Sandnessjøen, Norway, have been studied in detail during spring 2018 at NTNU (Norwegian University of Science and Technology), Trondheim. An overview of the experimental program can be found in $[27,28]$. As supplement to the study, selected devices were tested, and the acquired data were analysed. 


\subsection{Concrete beams}

In 1993, the Norwegian Public Roads Administration established a field station in Sandnessjøen in Northern Norway for testing of 17 different concrete recipes in coastal climate. All concrete beams were cast in November 1993 and mounted on a kay for exposure to sea water in spring 1994. Part of the beams have been clamped together to achieve a three-point-bending crack pattern. The concrete beams had dimensions of $3000 \times 300 \times 150 \mathrm{~mm}$. They were reinforced with one layer of reinforcement $\varnothing 16 \mathrm{~mm}$. The concrete cover was $25 \mathrm{~mm}$ from the top side and 125 $\mathrm{mm}$ from the bottom side of the concrete beams. The drawings of the beams are given in Figure 3. Plastic spacers were used to keep the reinforcement in place during casting of the beams. During exposure, the beams hanged vertically from a kai. The lower part of the beam was permanently submerged in seawater, the middle part was subjected to tidal changes and the upper part was in the atmospheric zone. Detailed information about the field station can be found in [29, 30].
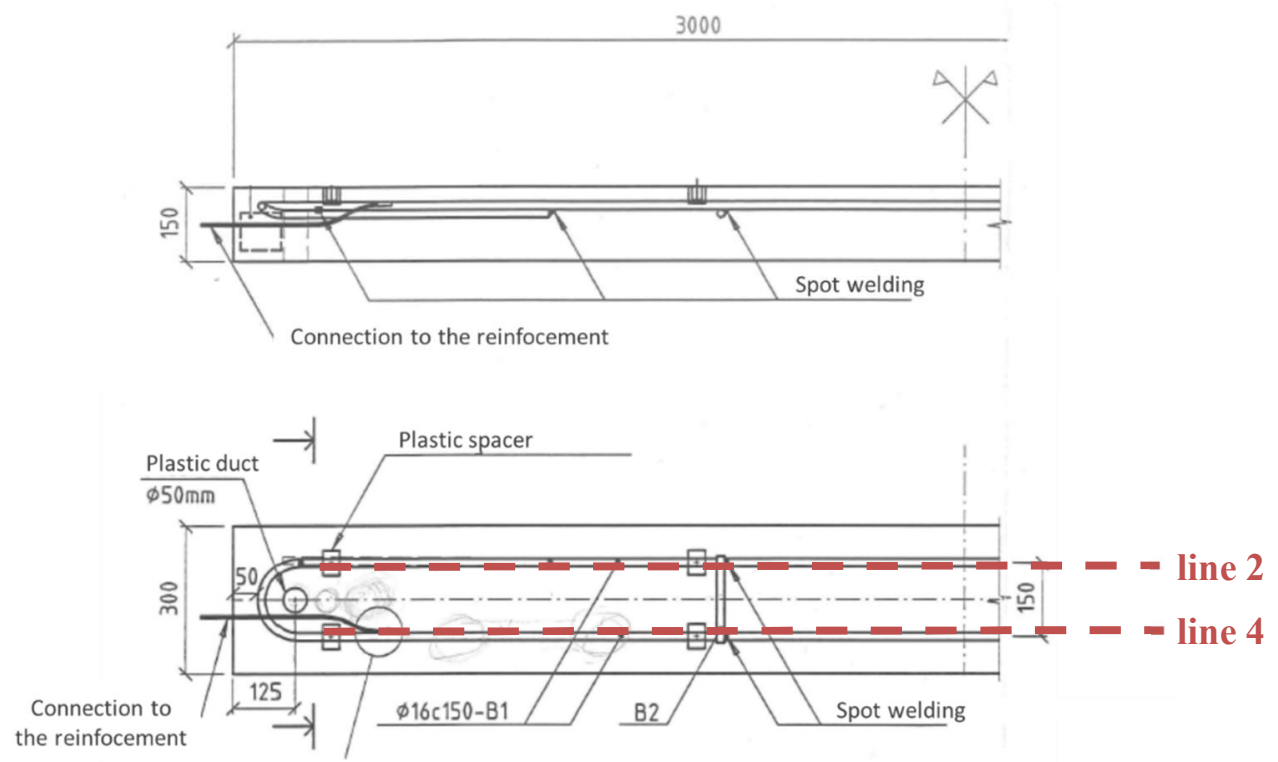

Figure 3 - Construction drawings of the beams, after [29], measures in [mm].

Three recipes were chosen for detailed investigations 25 years after initial exposure. The beams were transported to NTNU in spring 2018. The recipes chosen were concrete mix B (Portland cement with $4 \%$ silica fume and a water-to-binder ratio of 0.4 ), concrete mix E (Portland cement with $4 \%$ silica fume and $20 \%$ fly ash and a water-to-binder ratio of 0.4 ) and concrete mix $\mathrm{F}$ (Portland cement with $12.5 \%$ silica fume and a water-to-binder ratio of 0.4 ). The beams are in the following named beam B, E and F. For detailed information about the transport, storage and other studies undertaken at NTNU, the reader is referred to [31].

At the end of the above-mentioned studies at NTNU, the concrete cover of all beams was removed, and the actual state of the reinforcement was assessed. These data are used for benchmarking the measurements undertaken with different NDT techniques. All measurements reported in this paper were executed on $3^{\text {rd }}$ April 2018 on beam B, E and F along measurement lines 2 and 4 (cf. Figure 3). The beams were stored, packed tightly in plastic, in a $5^{\circ} \mathrm{C}$ climate room. The beams 
were brought to the lab (ca. $20^{\circ} \mathrm{C}$ ) approximately one hour before the first measurements. During the whole time of testing, the beams were cold on the surface. Detailed temperature measurements were not been performed. Measurements were started with beam B, followed by F and E. At the end of the measuring period (approximately 6 hours), parts of the measurements on beam $F$ were repeated to determine the temperature influence. The repeated measurement indicated that changes in concrete temperature over the testing period were limited and did not significantly influence the results.

\section{2}

\section{Measurement devices and procedures}

For measuring electrochemical potential, concrete resistivity and corrosion rate various commercial devices are available on the market. Three devices were used in this study: one device for measuring electrochemical potential (EP device), one device for measuring electrical resistance (ER device) and one device for measuring electrical resistance, potential and corrosion rate in the same operation ("all-in-one" device). In the following the devices and measurement proceedings are briefly described.

\section{Device for measuring electrochemical potential (EP device)}

The device used measures corrosion potentials with a cooper/cooper-sulphate (CSE) reference electrode provided as a rod or wheel electrode. The electrodes must be maintained regularly by renewing the electrolyte and assuring moist contact media. Electrical connection between the reinforcement and the measurement device as well as between the reference electrode and the device must be established. For potential measurements, it is recommended to map the reinforcement prior to measuring. Preferably, measurements are undertaken parallel and above the reinforcement. For this test, the wheel electrode of the device was used. The measurements were done along lines 2 and 4 (cf. Figure 3) in a distance of $50 \mathrm{~mm}$. No pre-wetting of the beams was necessary. The measurements took about two minutes per line with the used device as potentials are picked up automatically while slowly driving the electrode wheel over the concrete surface.

Device for measuring electrical resistance (ER device)

The device used is a simple four electrode measurement (based on the Wenner technique [32, 33], cf. Figure $1 \mathrm{~b}$ )) with a probe spacing of $50 \mathrm{~mm}$. The device is an easily applicable equipment, no preparation is in necessary. For good contact between the device and the concrete surface, wetted sponges were used on the probes of the equipment. It is recommended to perform 4-electrode resistance measurements in between the reinforcement. For the beams investigated, the concrete resistivity was measured in three areas of each beams: atmospheric zone ( $0,4-0,8 \mathrm{~m}$ from top), tidal zone (1,4 - 1,8 $\mathrm{m}$ from top) and submerged zone (2.4 - 2.8 $\mathrm{m}$ from top). The measurements were performed between lines 2 and 4 (cf. Figure 3 ) to avoid interference with the reinforcement. Per area, 6-8 measurement were performed, slightly changing the position of the equipment for each measurement. In total, about 10 minutes per beam were needed to perform all measurements. 


\section{"All-in-one" device}

The device offers the possibility to measure potential, resistivity and corrosion rate. The instrument consists of a measurement unit with six steel rods and one reference electrode. Measurements of resistivity and corrosion rate can be done in $\mathrm{x}$ and $\mathrm{y}$ direction, potentials are recorded in the origin. For the potential measurements, the device uses a maintenance-free electrode (unknown type) which is placed in the middle of the measurement unit (rod electrode type). Potentials are displayed vs. cooper/cooper-sulphate reference electrode. For corrosion rate measurements, the device uses a four-electrode setup. A constant AC current is applied between the outer electrodes and the voltage between the inner electrodes is measured. The frequency of the $\mathrm{AC}$ current is swept from a low frequency to a high frequency, the voltage responds of the system is recorded and can be interpreted (the method is in detailed described in [34]). For this method it is required to place the four measurement electrodes parallel to and above the reinforcement. For the resistivity measurements the same four electrodes are used. The resistivity measurements are, according to the supplier compensated for the influence of the reinforcement (as they are, against common suggestions, undertaken parallel to and above the reinforcement). Per measurement point all three parameters (per direction) can be acquired at the same time. For the measurements with the device, it is required to map the reinforcement layout. It must be noted that the equipment used here applies a newly developed technique for measuring corrosion rate which is not as well established as the techniques described in section 1.1. Measurements with the "all-in-one" device were performed along lines 2 and 4 (cf. Figure 3). Before starting the measurements, both the reference electrode and the steel electrodes were provided with wetted sponges to establish good contact to the concrete surface. Initially, a measurement interval of $100 \mathrm{~mm}$ was chosen, later the interval was increased to $200 \mathrm{~mm}$ to reduce the measurement time. In total, between 20 and 30 minutes were needed to map one beam. Measurements were only taken in the $\mathrm{x}$-direction according to the reinforcement layout.

\section{RESULTS}

\section{1 $\quad$ Electrochemical potentials}

The results of electrochemical potential measurements performed with the "all-in-one" device and EP device are presented in Figure $4-6$.

On beam F, the potential measurements were repeated approximately 6 hours after the initial measurements. The results are presented in Figure 7 and compared to the results of the initial measurement presented in Figure 6. These additional measurements were done to assess the possible effect on the measurements of changing temperature (after moving from climate room at $5^{\circ} \mathrm{C}$ to the laboratory at $20^{\circ} \mathrm{C}$ ). The data illustrate that change in room temperature had a limited impact on the measured potentials during the testing period. Accordingly, the sequences in which the beams were measured after they were moved from the climate room to the laboratory should not have influenced the results. 
Nordic Concrete Research - Publ. No. NCR 62 - ISSUE 1 / 2020 - Article 3, pp. 41-61

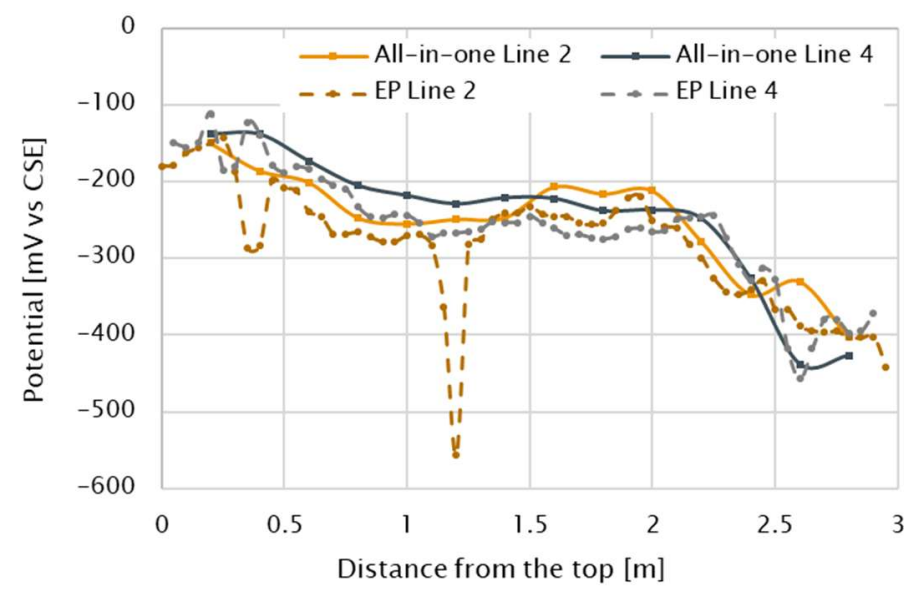

Figure 4-Electrochemical potential, beam $B$.

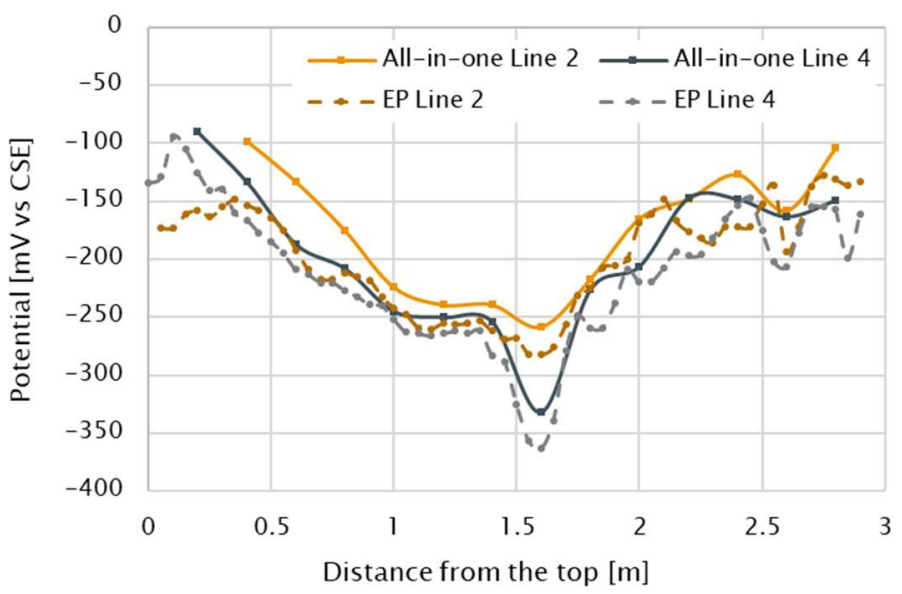

Figure 5 -Electrochemical potential, beam E.

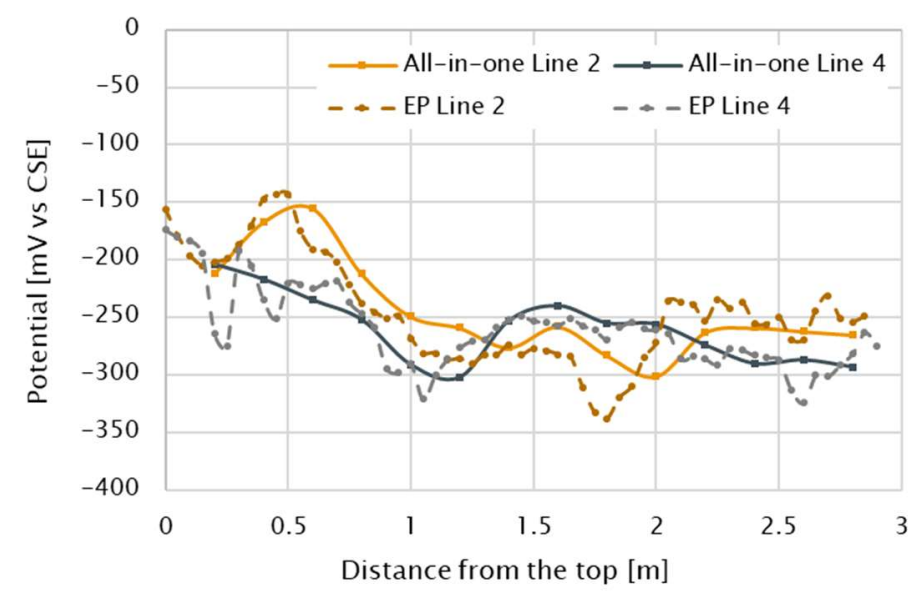

Figure 6-Electrochemical potential, beam F. 
Nordic Concrete Research - Publ. No. NCR 62 - ISSUE 1 / 2020 - Article 3, pp. 41-61

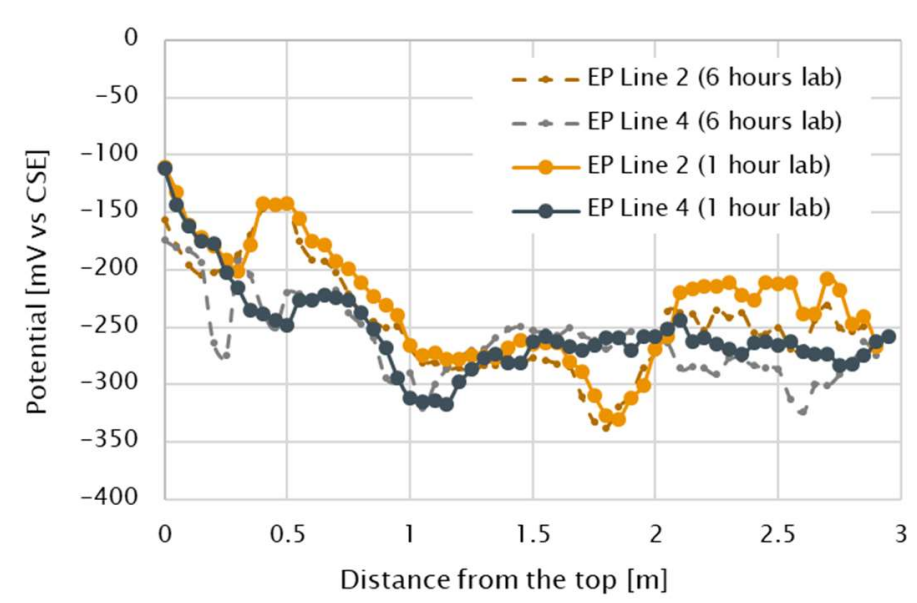

Figure 7 -Electrochemical potential, beam F, 1 and 6 hours after the beams were brought form the climate room $\left(5^{\circ} \mathrm{C}\right)$ to the lab $\left(20^{\circ} \mathrm{C}\right)$.

\subsection{Concrete resistivity}

The measurements of concrete resistivity with the two different devices used are presented in Figure $8-10$. For the «all-in-one» device the measurements are shown for the respective measurement points along lines 2 and 4. For the ER device the average of 6-7 measurements over a respective area of $0.4 \mathrm{~m}$ between lines 2 and line 4 as well as the measurement range (maximum and minimum measured value) are shown.

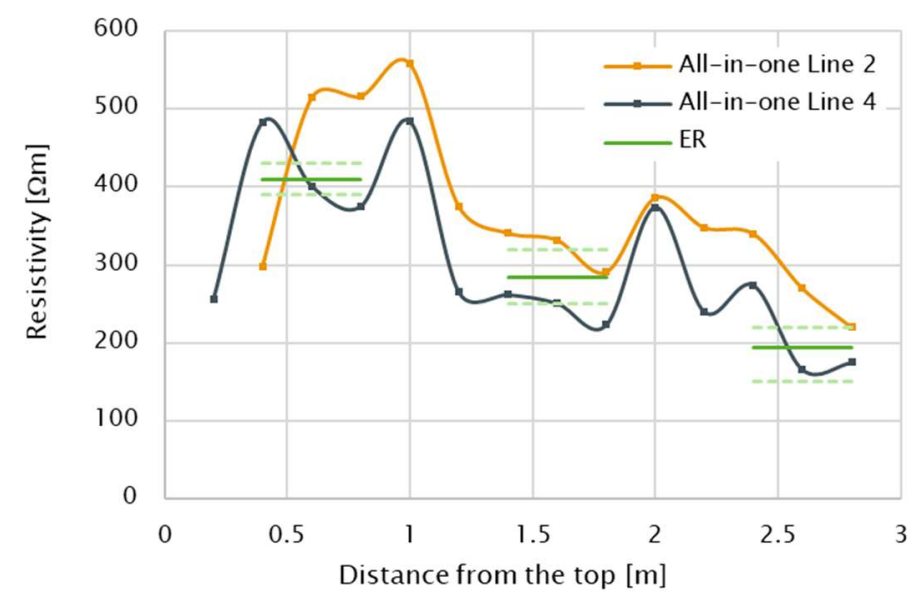

Figure 8 -Concrete resistivity, beam B. For the ER device, green full lines represent the average value, dotted lines represent the max. and min. value measured. 
Nordic Concrete Research - Publ. No. NCR 62 - ISSUE 1 / 2020 - Article 3, pp. 41-61

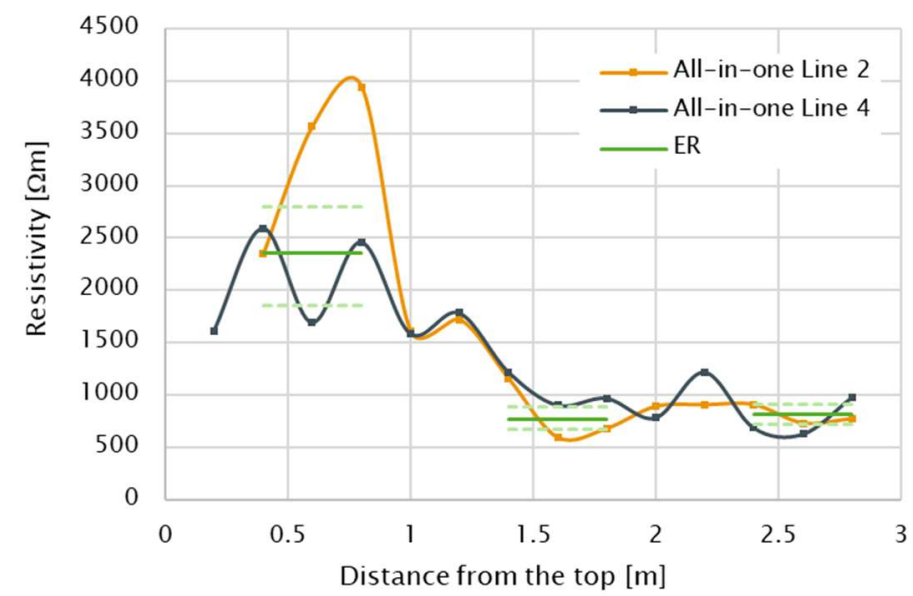

Figure 9-Concrete resistivity, beam E. For the ER device, green full lines represent the average value, dotted lines represent the max. and min. value measured.

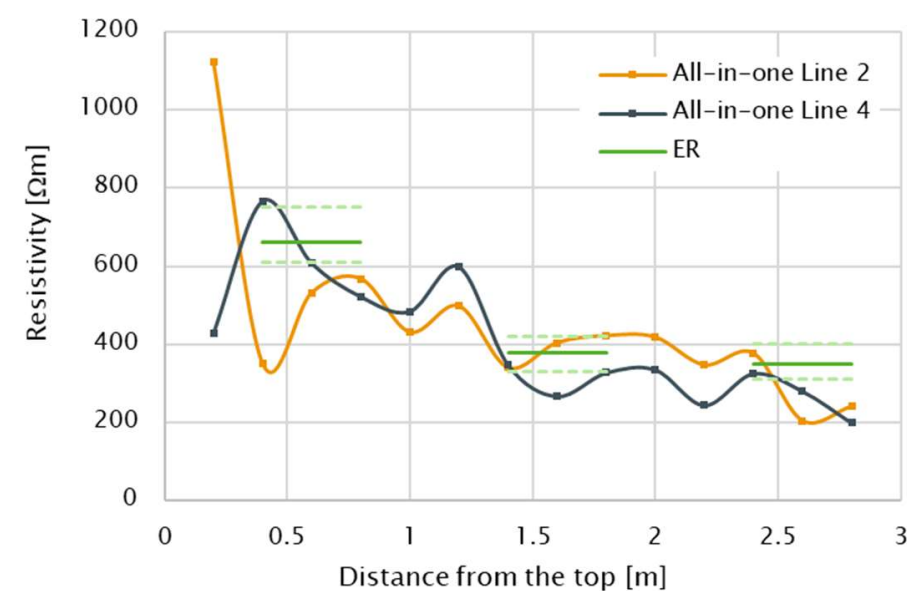

Figure 10 - Concrete resistivity, beam F. For the ER device, green full lines represent the average value, dotted lines represent the max. and min. value measured. 
Nordic Concrete Research - Publ. No. NCR 62 - ISSUE 1 / 2020 - Article 3, pp. 41-61

\section{3}

\section{Corrosion rate}

The corrosion rate was measured with the «all-in-one» device. The measurements are presented in Figures $11-13$.

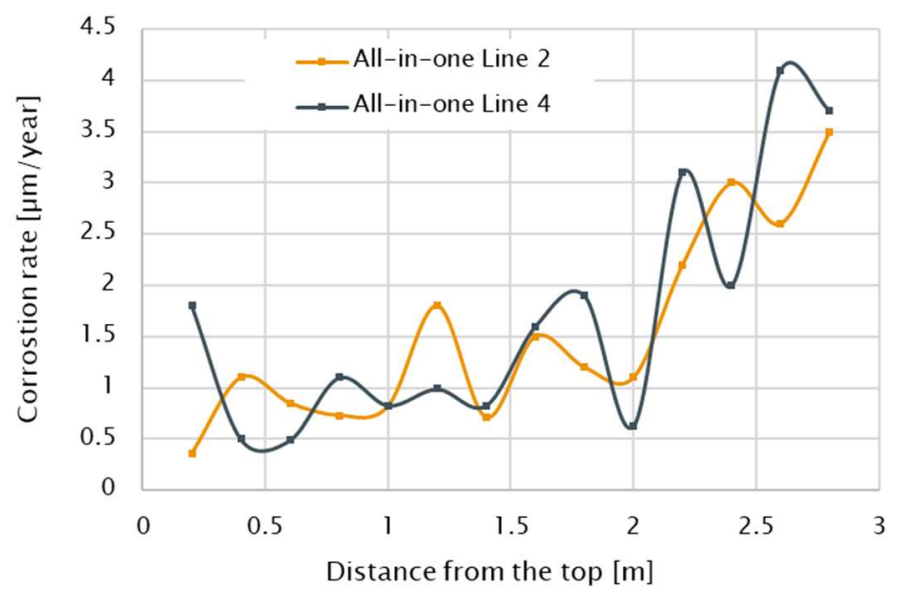

Figure 11 - Corrosion rate, beam $B$.

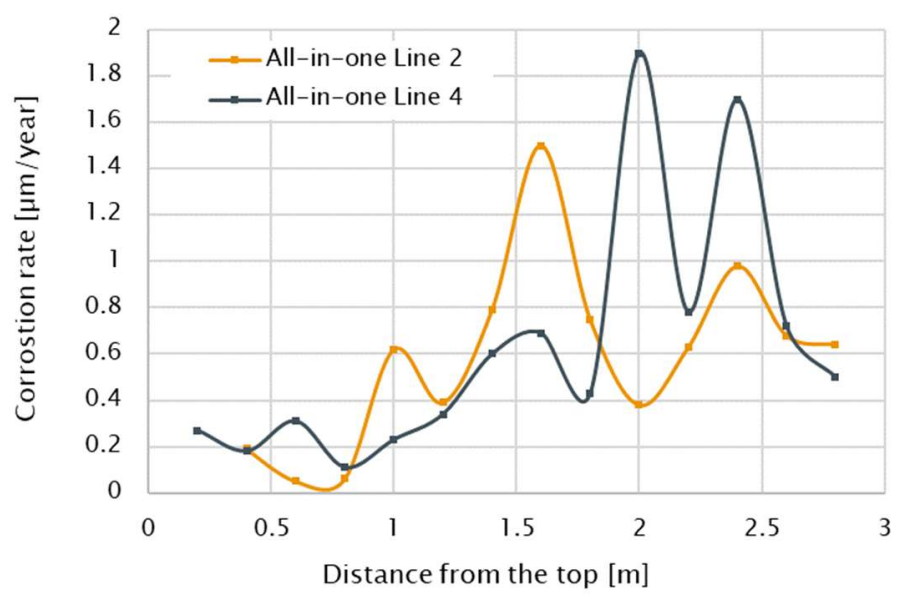

Figure 12 - Corrosion rate, beam E.

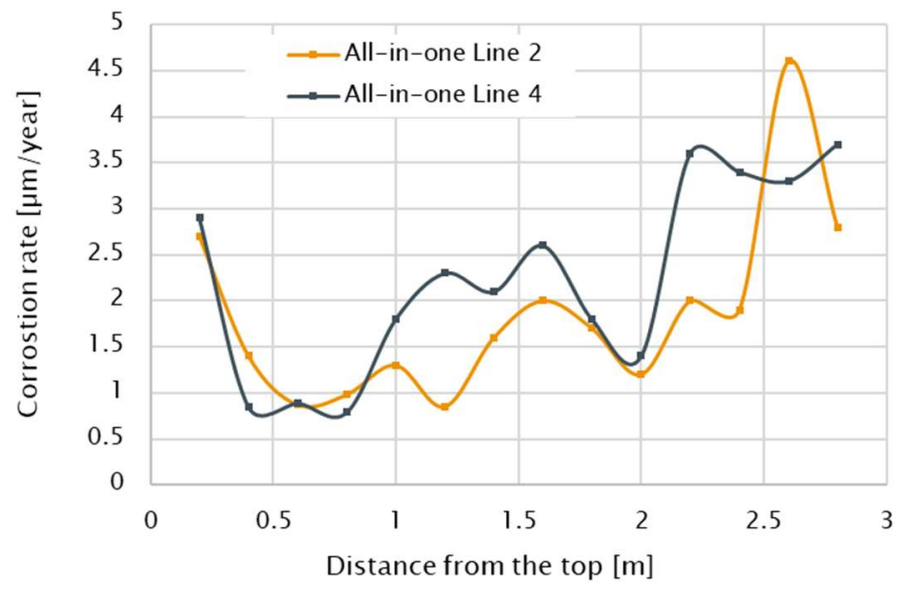

Figure 13 - Corrosion rate, beam F. 
All reinforcement bars were inspected after removing the concrete from the beams at the end of the testing period. The steel was generally in a good state. Figure 14 shows the corrosion map of the three investigated concrete beams. Corrosion was mainly found in the tidal zone, while limited corrosion was found in the submerged zone. In the figure, small distributed pitting is defined as small pits with a depth and width of $<0.5 \mathrm{~mm}$. Pitting refers to corrosion pits of a depth between 1 and $6 \mathrm{~mm}$ and a width of 2 to $48 \mathrm{~mm}$. Traces of superficial rust were observed over the entire reinforcement, independently of cracks and spacers. A detailed description and pictures of all corrosion spots can be found in [27, 28].
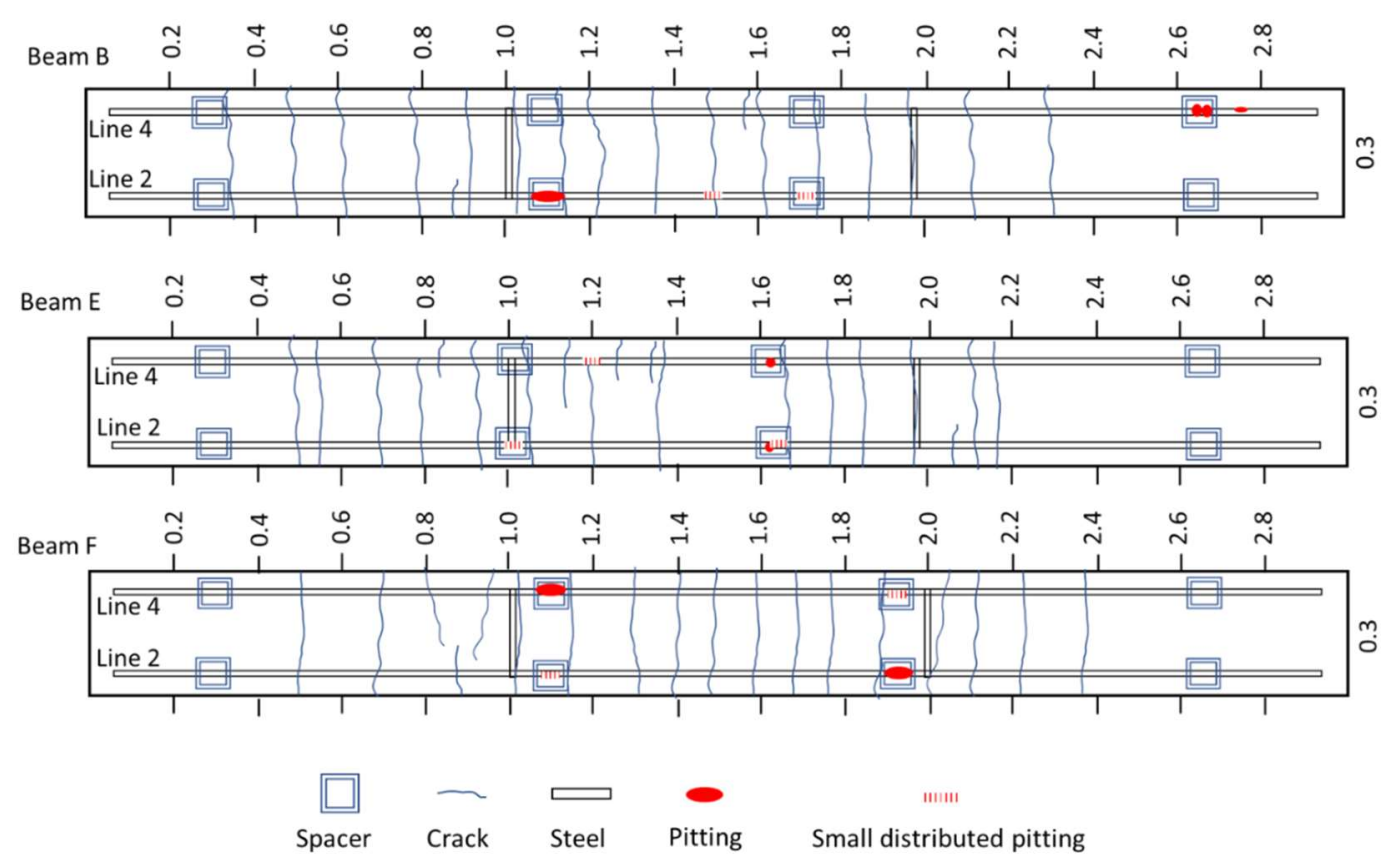

Figure 14 - Corrosion maps of beam B, E and F

In beam $B$, severe pitting corrosion was found at the location of one spacer in the tidal zone (line $2 ; 1.1 \mathrm{~m}$ from top) and one spacer in the submerged zone (line $4 ; 2.7 \mathrm{~m}$ from top). Additionally, small distributed pitting was found at one spacer (line 2; $1.7 \mathrm{~m}$ from top) and one crack (line 2; $1.5 \mathrm{~m}$ from top) in the tidal zone.

In beam E pitting was found at two spacers in the tidal zone (lines 2 and 4;1.6 $\mathrm{m}$ from top). Small distributed pitting was found at one spacer in the tidal zone (line 2;1.0 m from top) and one crack (line $4 ; 1.2 \mathrm{~m}$ from top)

In beam F, severe pitting corrosion was found at two spacers in the tidal zone (line $4 ; 1.1 \mathrm{~m}$ and line $2 ; 1.9 \mathrm{~m}$ from top). Small distributed pitting was found at the other two spacers in the tidal zone (line $4 ; 1.9 \mathrm{~m}$ and line $2 ; 1.1 \mathrm{~m}$ from top).

The results show that corrosion preferably started close to plastic spacers in the tidal zone of the beams. This observation is in detailed discussed in [28]. The corrosion observed was pitting 
corrosion. Although, limited in size, it is comparable to what can be observed in marine exposed structures and/or structures exposed to de-icing salts. Therefore, the findings of this study are considered generally applicable also for other cases of chloride induced reinforcement corrosion.

\section{4.}

\section{DISCUSSION}

All three parameters: electrochemical potential, concrete resistivity and corrosion rate are commonly suggested in literature to be used for evaluating the corrosion condition of reinforced concrete structures. In the following, the ability to detect corrosion is discussed by comparing the measured parameters with the actual corrosion state of the beams. The general practice related applicability and handling of the devices is commented at the end of the section. Again, it must be underlined that the results of the investigation should not be used for commercial purposes and that they are limited to the selected techniques applied in this study.

\subsection{Corrosion assessment using electrochemical potential}

Electrochemical potential measurements are based on corrosion activity leading to polarisation of steel which can be detected when mapping the potential. However, potentials are also influenced by other parameters as temperature and especially the moisture content and oxygen availability. For the actual case, the different exposure of the upper and lower part of the beams (atmospheric and submersed zone) can influence the potential without necessarily indicating active corrosion. Commonly, it would have been suggested to divide the dataset according to different exposure to avoid the influence of moisture and oxygen availability on the analyses of the measurements. Considering the limited amount of data and the comparable resistivity in the tidal and submerged zone, this has not been done here. If such is done, calibration of the measurements by excavations must be done in all exposure zones.

The potentials were both treated statistically $[5,6]$, plotted as potential maps and compared to the tabulated values in ASTM C 876 [4]. For data analyses the results measured with the EP device were used, as more data in a finer grid were collected. Analyses are shown in Figure $15-17$.

In part a) of Figures 15 - 17, potential maps are compared to the actual corrosion condition of the beams. The maps are shown with 3 colour levels, for beam B with $200 \mathrm{mV}$ intervals and for beam $\mathrm{E}$ and $\mathrm{F}$ with $100 \mathrm{mV}$ intervals. Potential gradients indicated by colour changes from orange to red in the maps (cf. Figures 15 - 17 a)) agree very well with the pits identified when opening the beams. For all beams, all corrosion spots can be detected when analysing the potential maps. For beam $\mathrm{B}$ according to the potential maps one may have expected a somewhat larger amount of corrosion in the submerged part and on both reinforcement bars (lines 2 and 4). It is likely that the corrosion spot observed, polarized a larger part of the steel due to low concrete resistivity (see also discussion in [28]). For beam $\mathrm{E}$ the largest corrosion spot was found in the middle of the beam $(1.6 \mathrm{~m})$ on line 4 . This is in accordance with the potential map. For beam F corrosion was 
found at lines 2 and 4 at around $1.1 \mathrm{~m}$ and $1.9 \mathrm{~m}$ from the top, also visible in the maps. Based on the maps areas with active corrosion would also have been expected in the submerged part of the beam $\mathrm{F}$, this was however not confirmed from the excavation. Areas with small disturbed pitting (cf. Figure 14) are not visible in the maps. This shows that either corroding areas must reach a certain size before they polarize the reinforcement sufficiently to cause measurable potential changes or that the measurement grid should have been finer.

In the Figures $15-17$ part b), both the frequency and cumulative curves are shown, data are grouped in intervals of $20 \mathrm{mV}$. Data are analysed in two ways:

- The frequency distribution plot is used to show the presence and percentage of actively corroding and passive rebars. Based on the assumptions that the potential values for both passive and active steel show a normal probability density distribution and that the mean potential value for actively corroding steel is significantly more negative than that for passive steel $[5,6]$.

- The cumulative frequency distributions are used for identifying threshold values, observed at shifts in the slope of the cumulative curve.

For more detailed information about methods of analysing data statically it is referred to the literature $[5,6]$. The method was, however, only successful for beam B (shown as grey area in Figure 15). For beam $\mathrm{E}$ and $\mathrm{F}$ the data could not be analysed with the method as it was not possible to differentiate distinct groups with high and low potentials. For beam B, the data from the statistical evaluation gave a mean value for active corrosion of $-385 \mathrm{mV}$ (first hump in the frequency distribution plot), the mean value for passive conditions was $-236 \mathrm{mV}$ (second hump in the frequency distribution plot). There are also clear shifts in the slope of the curve for the cumulative frequency distribution for the identified potential ranges. The suggested potential areas for active corrosion from the analyse are in good accordance with the actual observed corrosion locations (cf. Figure 4 and Figure 14). As sated before, for beam E the data is not as clear. One may expect some corrosion below $-300 \mathrm{mV}$ vs. CSE (first hump). Potentials above $-280 \mathrm{mV}$ may be interpreted as passive range. Also, the cumulative frequency distribution supports this assumption. However, as mentioned before a detailed analyse according to [5, 6], was not possible as there were not enough data in the lower potential range. Beam $\mathrm{F}$ does not show two distinct humps in the frequency plot or a shift of slopes in the cumulative frequency distribution, suggesting no active corrosion in the beam. However, corrosion was observed at several places. 


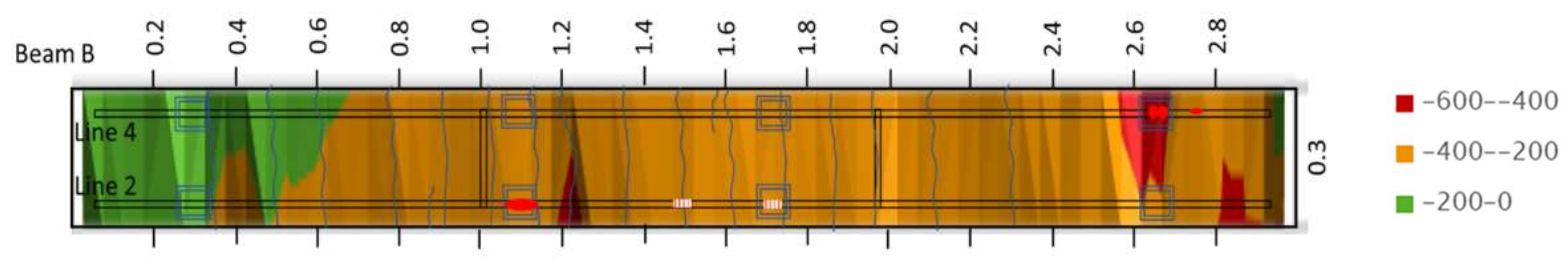

a)

b)

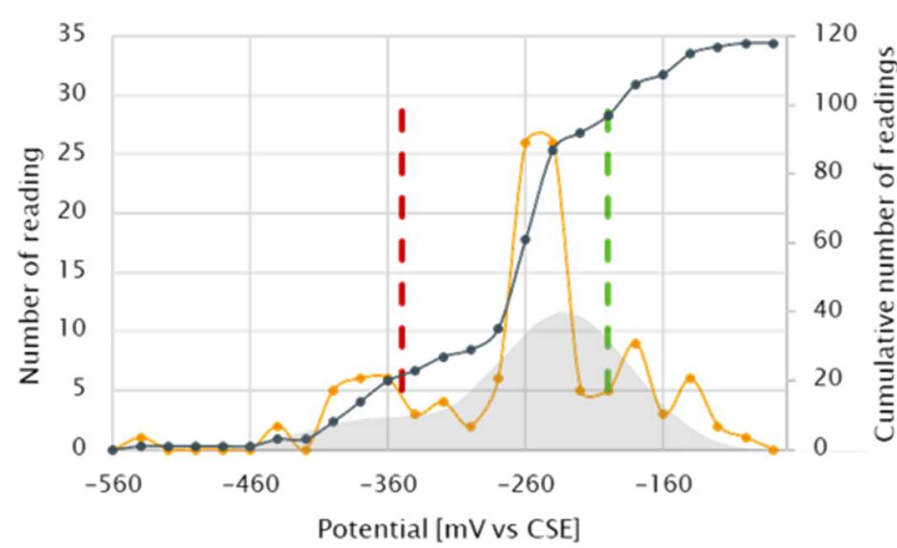

Figure 15 - Interpretation potential measurements, beam B. a) Potential map and actual corrosion condition of the beam (cf. Figure 14). b) Black line-cumulative frequency distribution, orange line - frequency distribution, red and green dashed lines - lower and upper threshold according ASTM C876. Grey shadow, data analyse according to [5, 6], mean value active corrosion $-385 \mathrm{mV}$, mean value passive condition $-236 \mathrm{mV}$

a)

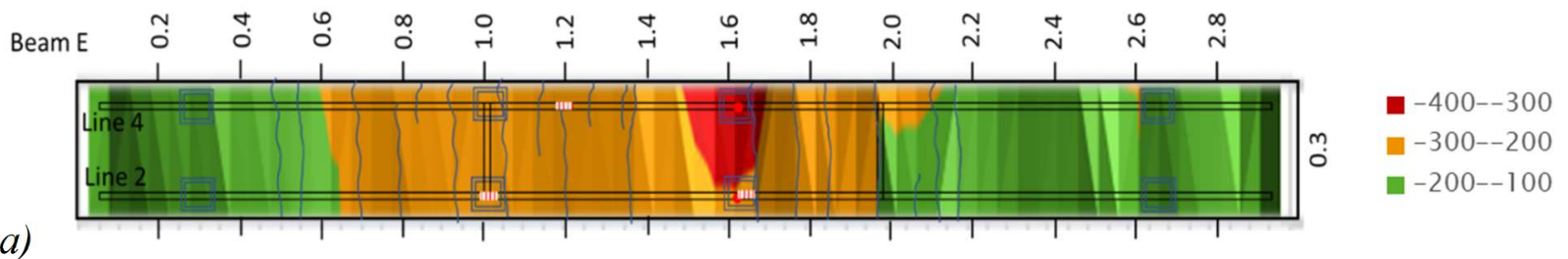

b)

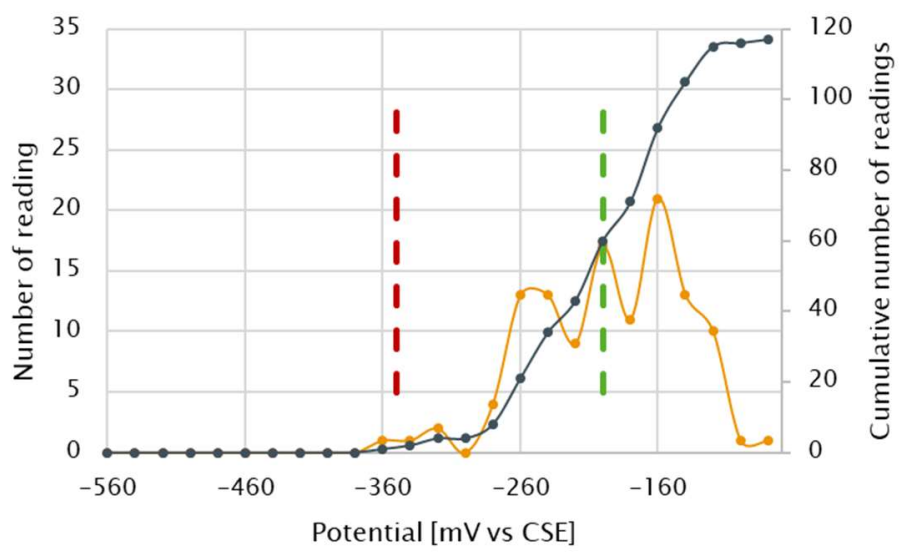

Figure 16 - Interpretation potential measurements, beam E. a) Potential map and actual corrosion condition of the beam (cf. Figure 14). b) Black line-cumulative frequency distribution, orange line - frequency distribution, red and green dashed lines - lower and upper threshold according ASTM C876. 
a)

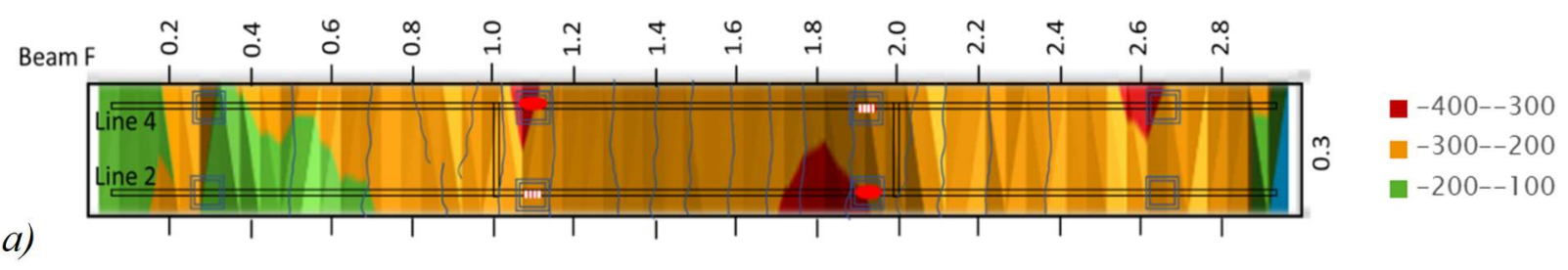

b)

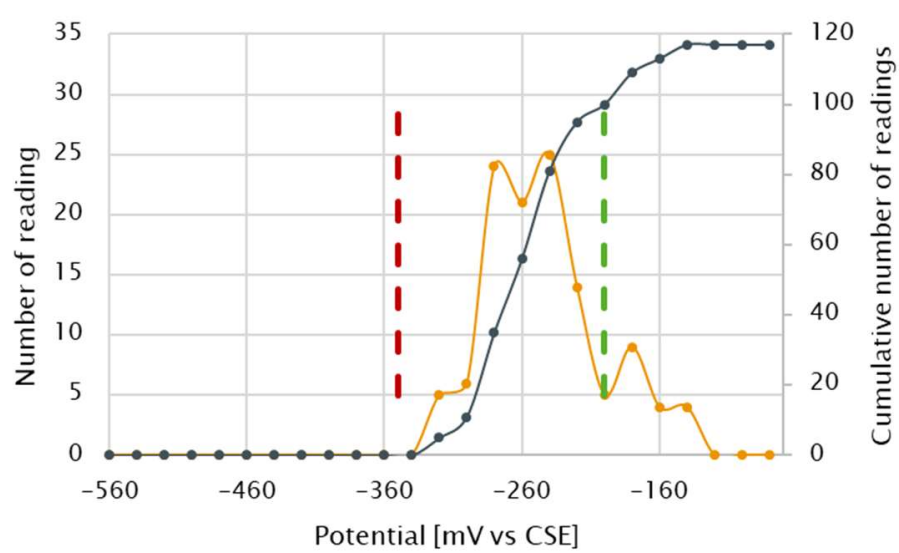

Figure 17 - Interpretation potential measurements, beam F. a) Potential map and actual corrosion condition of the beam (cf. Figure 14). b) Black line-cumulative frequency distribution, orange line - frequency distribution, red and green dashed lines - lower and upper threshold according ASTM C876.

The analyses shown in Figures $15-17$ part b) include the threshold values proposed by ASTM C 876 [4]. According to the standard, values above $-200 \mathrm{mV}$ vs. CSE indicate that the probability that the probability for corrosion is lower than $10 \%$, for values between $-200 \mathrm{mV}-\quad-350 \mathrm{mV}$ vs. CSE corrosion activity is uncertain, and for values below $-350 \mathrm{mV}$ the probability for corrosion is higher than 90\%. The threshold values according to ASTM C876 [4] are valid for outdoor exposure including chloride exposure however it is stated that they are not applicable to concrete structures that are water-saturated or in near-saturated conditions. The concrete investigated here, was partly submerged and has a high moisture content $[27,28]$, accordingly the thresholds are technically not suited for the analyses here. Elsener\&Bohni [35] summarised data for various structures, showing about $200 \mathrm{mV}$ lower potential ranges indicating corrosion compared to the ASTM C876 thresholds for a column in seawater. The potential values given as threshold in the ASTM recommendation would give the assessment of uncertain corrosion risk for most potentials measured. Only for beam B the threshold values indicate high corrosion risk in some places. Again, it must be noted that the thresholds are not directly applicable for the exposure conditions of the beams.

In conclusion it was found that potential measurements gave a good prediction of the corrosion state of beams B, and partly also beam E both when data was shown in maps and as frequency distribution curves. This, although the data were not separated according to exposure as it would have been recommend. This can most likely be explained by a higher polarization of the steel due to active corrosion than due to the varying exposure. The corrosion condition of beam F was more difficult to assess. For the frequency distribution curve, no distinct area with active corrosion could be identified. During a field inspection, a further step could have been to calibrate the 
measurements in spots of low and high potentials. In the case of beam $\mathrm{F}$ low potentials were found around $1.8 \mathrm{~m}$ from the top on line 2 , and $1 \mathrm{~m}$ and $2.6 \mathrm{~m}$ from the top on line 4 . Opening these areas would have reveal corrosion spots and the collected data could have been re-analysed based on the observations. This illustrates the importance of supplementing and calibrating NDT data with selected excavations. Also, if more data would have been available, differentiating areas of different exposure (here atmospheric and, tidal and submerged zone) could have led to a more specific analyse of the data.

\subsection{Corrosion assessment using corrosion rate}

The corrosion rate measurements should confirm the potential measurements, showing areas with high corrosion rates where low potentials are found. According to common suggestions, corrosion rates below 1-2 $\mu \mathrm{m} /$ year can be neglected. For values between 1 and $5 \mu \mathrm{m} /$ year low corrosion activity are expected while a moderate corrosion activity is suggested for values between 5 and $10 \mu \mathrm{m} /$ year $[1,13]$. Accordingly, the measurements for beam B performed with the «all-in-one» device, suggest corrosion with a low rate in the submerged part ( $>2 \mathrm{~m}$ distance from the top, cf. Figure 11) and else negligible rates of corrosion. Corrosion spots identified by the potential measurement in the middle of the beam are not found in the corrosion rate measurements, most likely due to a too large measurement grid used for the "all-in-one" device. For beam E, according to the corrosion rate measurements no active corrosion spots are expected (cf. Figure 12). Although, the potential measurements indicate a potential drop in the middle of the beam line 4, the corrosion rate measurements do not show significant higher corrosion rates in this area. For beam $\mathrm{F}$, the corrosion rate is above $2 \mu \mathrm{m}$ /year at several locations, both in the submerged part and in the tidal zone of the beam, suggesting corrosion with a low rate. However, no corrosion was found in the submerged part of the beam when removing the concrete. The corrosion rate measurements had in general a rather high scatter and were difficult to analyse. It must be noted that the equipment used in this study, applies a new and so far not much used technique with limited practice experience.

\subsection{Corrosion assessment using concrete resistivity}

Concrete resistivity alone cannot provide information about the state of the reinforcement. Resistivity data can, however, indicate where corrosion rates are expected to be high if potential measurements indicate active corrosion. For all three beams the corrosion rate data were compared with the concrete resistivity data, results from the «all-in-one» device were used for the comparison, see Figure 18.

A trend of increasing corrosion rates with decreasing concrete resistivity can be observed, however the data has a high scatter and is difficult to analyse. This can both be explained by the variations in the corrosion rate measurements (cf. section 4.3) and by the earlier reported limitations of the direct comparison of corrosion rate and concrete resistivity [36-38]. 
Nordic Concrete Research - Publ. No. NCR 62 - ISSUE 1 / 2020 - Article 3, pp. 41-61

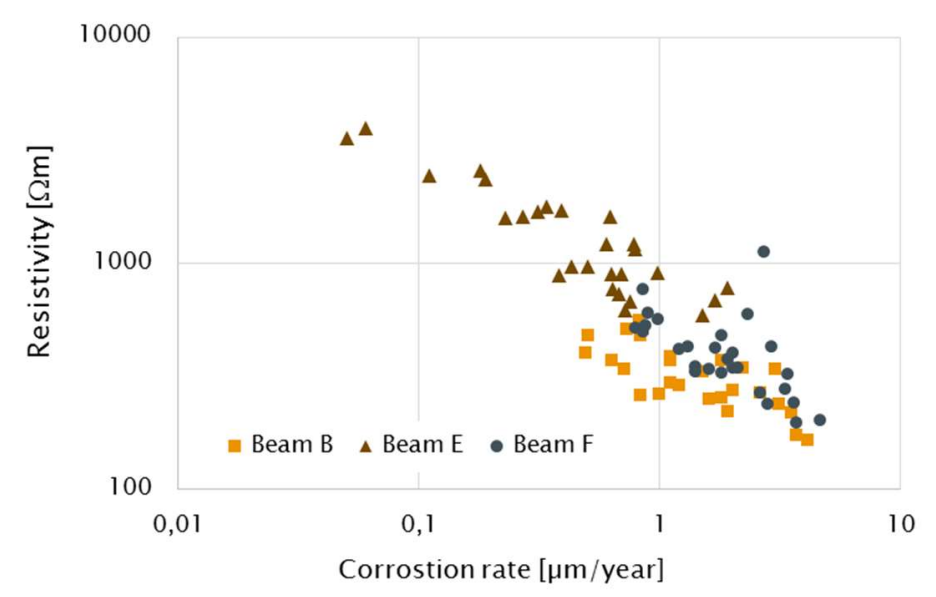

Figure 18 - Comparison between concrete resistivity and corrosion rate, beam $B, E$ and $F$.

\subsection{Practice applicability of the used devices}

The measurements of the electrochemical potential are based on the same principle and executed in the same way for both devices used in the study and as expected the data are in good agreement (cf. Figure 4 - 6). Variations up to about $70 \mathrm{mV}$ between measurements at the same locations can be observed, although they are not considered significant, it underlines the need for calibration. For beam B, a distinct drop in potential around $1.2 \mathrm{~m}$ distance from the top can be seen (cf. Figure 4) for the measurements taken with the EP device. The «all-in-one» device could not pick up this point, probably because of the too large grid size $(200 \mathrm{~mm}$ compared to $50 \mathrm{~mm}$ with the EP device). This illustrates that small corrosion spots can be "overseen" when using large grid size and underlines for the importance of a small grid size. Also, the methods of measuring concrete resistivity used in the two devices are based on the same principle, and the devices have a comparable electrode distance. However, with the «all-in-one» device measuring potentials and resistivity simultaneously, resistivity measurements are performed parallel to and over the reinforcement which is commonly not advised. The instrument and software compensate for the influence of the reinforcement when calculating the results. The technique seems applicable as the data from the two devices are comparable for all beams (cf. Figure $8-10$ ). With the «all-inone» device it is possible to observe the resistivity distribution over the length of the beam in more detail than what was possible with the simple EP device used here.

The «all-in-one» device enables the measurement of three parameter during the same operation which is the main advantage of the device. However, much more time was needed to execute the measurements per beam compared to the other devices used, even though using a larger grid width (i.e. less measurement points). In conclusion, all devices offer benefits, but also have limitations. Skilled operators can map the concrete surface and acquire data uncomplicated no matter which equipment is used. 
Among the methods selected for this study, it was found that electrochemical potential measurements with a small grid size gave a good indication of the actual corrosion state in form of detecting active and passive reinforcement in the investigated marine exposed trial elements. Corrosion rate measured with a newly developed device and technique, and concrete resistivity measurements followed the trend of the potential measurements, however they had a much higher scatter and seemed generally more difficult to interpret. In the present study, they gave no additional information. As typically recommended, the concrete cover should be excavated in selected areas both for calibration of the electrochemical potential measurements and to obtain knowledge on the actual level of corrosion of the reinforcement.

\section{ACKNOWLEDGMENT}

Magda Osmolska (OsloMet, Oslo, Norway) is acknowledged for her help with analysing the potential data.

\section{REFERENCES}

1. Bertolini L, Elsener B, Pedeferri P, Redaelli E \& Polder R B: "Corrosion of Steel in Concrete: Prevention, Diagnosis, Repair", $2^{\text {nd }}$ Edition. Wiley-VCH Verlag GmbH \& Co, 2013.

2. Broomfield J P: "Corrosion of steel in concrete: understanding, investigation, and repair". 1. ed. E \& FN Spon. xxi, London and New York, 1997, 240 pp.

3. Elsener B, Andrade C, Gulikers J, Polder R B \& Raupach M: "Half-cell potential measurements - Potential mapping on reinforced concrete structures". Materials and Structures, Vol. 36, No. 261, 2003, pp. 461-471.

4. ASTM: "ASTM C876 Standard Test Method for Corrosion Potentials of Uncoated Reinforcing Steel in Concrete". 2015.

5. Gulikers J \& Elsener B: "Development of a calculation procedure for the statistical interpretation of the results of potential mapping performed on reinforced concrete structures". Materials and Corrosion-Werkstoffe Und Korrosion, Vol. 60, No. 2, 2009, pp. 87-92.

6. SIA: "Planung, Durchfuhrung und Interpretation der Potenzialmessung an Stahlbeton (in German)". Zurich, Switzerland, 2013,

7. Gjørv O E, Vennesland Ø \& El-Busaidy A H S: "Electrical Resistivity of Concrete in the Oceans". Proceedings, $9^{\text {th }}$ Annual Offshore Technology Conference, Houston, Texas, USAm 1977, pp. 581-588.

8. Bertolini L \& Polder R B: "Concrete resistivity and reinforcement corrosion rate as a function of temperature and humidity of the environment". TNO report, TNO Building and Construction Research. The Nethrelands, 1997.

9. Elkey W \& Sellevold E J: "Electrical resistivity of concrete". Norwegian Roads Research Laboratory, Oslo, Norway, 1995.

10. Whiting D A \& Nagi M A: "Electrical Resistivity of Concrete - A Literature Review". $R \& D$ Serial No. 2457. Portland Cemente Association: Skokie, Illinois, USA, 2003. 
11. Hornbostel K: "The role of concrete resistivity in chloride-induced macro-cell corrosion of reinforcement". Doctoral Thesis, Department of Structural Engineering, Norwegian University of Science and Technology (NTNU), Trondheim, Norway, 2015.

12. Polder R B: "Test methods for on site measurement of resistivity of concrete - a RILEM TC-154 technical recommendation". Construction and Building Materials, Vol. 15, No. 2-3, 2001, pp. 125-131.

13. Andrade C, Alonso C, Gulikers J, Polder R B, Cigna R, Vennesland $\varnothing$, Salta M, Raharinaivo A \& Elsener B: "Rilem TC 154-EMC: Electrochemical techniques for measuring metallic corrosion - Test methods for on-site corrosion rate measurement of steel reinforcement in concrete by means of the polarization resistance method". Materials and Structures, Vol. 37, No. 273, 2004, pp. 623-643.

14. Elsener B: "Corrosion rate of steel in concrete - Measurements beyond the Tafel law". Corrosion Science, Vol. 47, No. 12, 2005, pp. 3019-3033.

15. Stern M \& Geary A L: "Electrochemical polarization. I. A theoretical analysis of the shape of polarization curves.". Journal of the Electrochemical Society, Vol. 104, No. 1, 1957, pp. 56-63.

16. Bertolini L, Gastaldi M, Pedeferri M P, Pedeferri P \& Pastore T: "Effects of galvanic coupling between carbon steel and stainless steel reinforcement in concrete". Proceedings, International Conference on Corrosion and Rehabilitation of Reinforced Concrete Structures, Orlando, Florida, USA, 1998.

17. Nygaard P V, Geiker M R \& Elsener B: "Corrosion rate of steel in concrete: evaluation of confinement techniques for on-site corrosion rate measurements". Materials and Structures, Vol. 42, No. 8, 2009, pp. 1059-1076.

18. Raupach M: „Zur chloridinduzierten Makroelementkorrosion von Stahl in Beton“. Vol. Heft 433, Deutscher Ausschuss für Stahlbeton. Beuth Verlag GmbH, Berlin, Germany, 1992. (In German).

19. Jäggi S, Böhni H \& Elsener B: "Macrocell corrosion of steel in concrete - experiments and numerical modelling". In "Corrosion of reinforcement in concrete - mechanisms, monitoring, inhibitors and rehabilitation techniques". (M Raupach et al., Editors). Woodhead Publishing Limited / CRC Press, 2007, pp. 75-88.

20. Elsener B: "Macrocell corrosion of steel in concrete - implications for corrosion monitoring". Cement and Concrete Composites, Vol. 24, No. 1, 2002, pp. 65-72.

21. Angst U \& Büchler M: "On the applicability of the Stern-Geary relationship to determine instantaneous corrosion rates in macro-cell corrosion". Materials and CorrosionWerkstoffe und Korrosion, Vol. doi: 10.1002/maco.201407997, 2014.

22. Andrade C \& González J A: "Quantitative measurements of corrosion rate of reinforcing steels embedded in concrete using polarization resistance measurements". Materials and Corrosion-Werkstoffe und Korrosion, Vol. 29, 1978, pp. 515-519.

23. Andrade $\mathrm{C} \&$ Alonso C: "Corrosion rate monitoring in the laboratory and on-site". Construction and Building Materials, Vol. 10, No. 5, 1996, pp. 315-328.

24. Tang $\mathrm{L} \& \mathrm{Fu} \mathrm{Y}$ : "A rapid technique using handheld instrument for mapping corrosion of steel in reinforced concrete". Restoration of Buildings and Monuments, Vol. 12 (5-6), 2006, pp. 387-400.

25. Tang L \& Utgenannt P: "Verification of a rapid technique for corrosion measurement using reinforced concrete slabs after long-term field exposure". Proceedings, Concrete Platform 2007, Belfast, UK, 2007.

26. Hope B B, Page J A \& Ip A K C: "Corrosion Rates of Steel in Concrete". Cement and Concrete Research, Vol. 16, No. 5, 1986, pp. 771-781.

27. Danner T, Revert A B \& Gelker M R: "Field station Sandnessjøen. Effect of cracks in concrete after 25 years - Data report". Norway, 2020, 
28. Geiker M, Danner T, Michel A, Belda Revert A, Linderoth O \& Hornbostel K: "25 years' field exposure of pre-cracked concrete beams; combined impact of spacers and cracks on reinforcement corrosion.". Submitted to Cement and Concrete Research, 2020.

29. Isaksen H R \& Holtmon J P: "Rapport fra produksjon av prøveelementer". 94-13 BRU Vegvesen, Norway, 1994. (In Norwegian).

30. Liestøl G, Kompen R, Sellevold E J \& Isaksen H R: "Resepter og fasthet". 95-07 BRU Vegvesen, Norway, 1995. (In Norwegian).

31. Officials A A o S H a T. AASHTO T260 Standard method of test for sampling and testing for chloride ion in concrete and concrete raw materials. 2009.

32. Wenner F "A method of measuring earth resistivity". National Bureau of Standards, Bulletin 12 (4): Washington, USA, 1915, pp. 478-496.

33. Angst U M \& Elsener B: "On the Applicability of the Wenner Method for Resistivity Measurements of Concrete". ACI Materials Journal, Vol. 111, No. 6, 2014, pp. 661-672.

34. Fahim A, Ghods P, Alizadeh R, Salehi M \& Decarufel S: "CEPRA - A new test method for rebar corrosion rate measurement". STP: Selected Technical Papers, 2017.

35. Elsener B \& Bohni H: "Potential Mapping and Corrosion of Steel in Concrete". In: "Corrosion Rates of Steel tn Concrete, ASTM STP 1065". (N S Berke, V Chaker \& D Whiting, Editors). American Society for Testing and Materials, Philadelphia, USA, 1990, pp. 143-156.

36. Hornbostel K, Larsen C K \& Geiker M R: "Relationship between concrete resistivity and corrosion rate - A literature review". Cement and Concrete Composites, Vol. 39, 2013, pp. 60-72.

37. Hornbostel K, Angst U M, Elsener B, Larsen C K \& Geiker M R: "Influence of mortar resistivity on the rate-limiting step of chloride-induced macro-cell corrosion of reinforcing steel". Corrosion Science, Vol. 110, 2016, pp. 46-56.

38. Hornbostel K, Elsener B, Angst U M, Larsen C K \& Geiker M R: "Limitations of the use of concrete bulk resistivity as an indicator for the rate of chloride-induced macro-cell corrosion". Structural Concrete, Vol. 18, No. 2, 2017, pp. 326-333. 